\title{
Study of Chlorophyll-related Compounds from Dietary Spinach in Human Blood
}

\author{
Pi-Yu CHAO ${ }^{1}$, Meng-Yuan $\mathrm{HUANG}^{2}$, Wen-Dar HUANG ${ }^{3}$, \\ Kuan-Hung LIN ${ }^{4,5 *}$, Shiau-Ying CHEN ${ }^{5}$, Chi-Ming YANG ${ }^{6 * *}$ \\ ${ }^{1}$ Department of Nutrition and Health Sciences, Chinese Culture University, Taipei 111, Taiwan; pychao@faculty.pccu.edu.tw \\ ${ }^{2}$ Department of Horticulture and Biotechnology, Chinese Culture University, Taipei 111, Taiwan; a86229265@yahoo.com.tw \\ ${ }^{3}$ Department of Agronomy, National Taiwan University, Taipei 110,Taiwan;wendar@ntu.edu.tw \\ ${ }^{4}$ Faculty of Applied Sciences, Ton Duc Thang University, Ho Chi Minh City 700000, Vietnam; linkuanhung@tdt.edu.vn; \\ rlin@faculty.pccu.edu.tw (*corresponding author) \\ ${ }^{5}$ Graduate Institute of Biotechnology, Chinese Culture University, Taipei 111, Taiwan; lovely73125@hotmail.com \\ ${ }^{6}$ Biodiversity Research Center, Academia Sinica, Taipei 115, Taiwan; cmyang@gate.sinica.edu.tw ( ${ }^{* *}$ co-corresponding author)
}

\begin{abstract}
Human bioavailability data on chlorophyll (Chl) is very limited. The distribution of Chl-related compounds (CRCs) derived from dietary spinach was investigated in human blood. Eight healthy adults, aged from 21 to 61 year-old, consumed 1.2 $\mathrm{kg}$ of just-boiled fresh spinach after an 8-h overnight fast. Before and then $3 \mathrm{~h}$ after consuming the spinach, blood samples were taken from each participant. Freeze-dried blood samples were prepared, and $80 \%$ acetone was added for grinding. Eight peaks were found in the blood using high-performance liquid chromatography (HPLC), and the main CRCs in the samples were pheophytin (Phe) and pheophorbide (Pho) derivates. Compared to a fasted state, markedly higher levels of blood CRCs were detected in all subjects, except that Pho metabolites were not found in two subjects. No significant differences were seen in most of the peaks between males and females; however, relatively higher CRCs levels were observed in females, particular of Pho derivates. In addition, the blood contained significantly higher levels of Phe in the 36 61-year-old group than in the 21 35-year-old group. These results suggest that the conversion of Chls to CRCs is a rapid process, and Chls obtained by ingestion can be absorbed by the human body.
\end{abstract}

Keywords: chlorophyll; high-performance liquid chromatography; human bioavailability; pheophytin; pheophorbide; pigments

\section{Introduction}

Chlorophylls (Chls), the most abundant green pigments found in plants, are important in photosynthesis. Chls are constituents of the diet, and are naturally catabolized into two related chemicals, chlorophyllide (Chlide) and pheophorbide (Pho) (Hsu et al., 2014). The Chls found in green vegetables contain a porphyrin ring to which is attached a long-chain phytol tail, and in which an $\mathrm{Mg}$ ion is chelated. Removal of the phytol tail from Chl forms Chlide, and the removal of both the phytol tail and the chelated $\mathrm{Mg}$ atom forms Pho (Hsu et al., 2013). The chemical structures of the porphyrin ring of the Chls, $\mathrm{Chl} a$ and $\mathrm{Chl} b$, vary slightly, and they are respectively converted into pheophytin $a$ (Phe $a$ ), Chlide $a$, and Pho $a$, and Phe $b$, Chlide $b$, and Pho $b$ by chlorophyllase (chlorophyll-chlide hydrolase, Chlase, EC 3.1.1.14) (Lin et al., 2013). All of these photosynthesisrelated pigments (Chlide $a$ and $b$, Phe $a$ and $b$, and Pho $a$ and $b$ ) are called Chl-related compounds (CRCs) (Hsu et al., 2014).

These naturally occurring Chl derivatives are abundant in green vegetables and are known to have chemopreventative properties. Antimutagenic effects and antioxidative capacities of CRCs in tissue culture models were documented. For example, Subramoniam et al. (2012) demonstrated that Chl $a$ has antioxidant and antiinflammatory activities in human embryonic kidney 293 cells through inhibiting expression of the tumor necrosis factor- $\alpha$ gene. Chls are digested to Phe and then absorbed within the micelle fraction according to a caco-2 human-cell model (Ferruzzi et al., 2001). Chls that are taken up by 
310

myeloma cells are converted into Pho (Chernomorsky et al., 1999). Furthermore, application of Pho exhibited both effective antitumor and anti-inflammation activities in ICR mouse skin (Nakamura et al., 1996), and it acted as a photodynamic sensitizer against tumors in mice (Pandey et al., 1992). Previously, we reported that the antioxidative capacities of CRCs can protect human lymphocyte DNA from hydrogen peroxide-induced DNA damage ( $\mathrm{Hsu}$ et al., 2005). CRCs reduce oxidative stress and play roles in quenching 1,1-diphenyl-2-picrylhydrazyl (DPPH), chelating $\mathrm{Fe}(\mathrm{II})$, and preventing the formation of thiobarbituric acid-reactive substances (TBARSs) during $\mathrm{Cu}$-mediated peroxidation of low-density lipoprotein (LDL) in a dose-dependent manner (Hsu et al., 2013). Moreover, CRCs were also found to inhibit aflatoxin (AF)B1-DNA adduct formation and to suppress AFB1induced liver cancer in human murine hepatoma cells (Hsu et al., 2008). Recently, we showed that CRCs exert antiinflammatory activities through inhibiting expressions of the nuclear factor- $\kappa \mathrm{B}$ and signal transducer and activator of transcription 3 (STAT3) genes in human aortic endothelial cells (Lin et al., 2013).

The biodistribution and catabolism of CRCs have been assessed in animals and humans. In a study on the biodistribution of the palladium-bacteriochlorophyll derivative, WST11, hepatic clearance was demonstrated as the major pathway in mice with a melanoma (Mazor et al., 2005). Using rats, Bellnier $e t$ al. (1993) demonstrated the presence of the photosensitizer, 2-[1-hexyloxyethyl]-2devinyl pyropheophorbide-a (HPPH), in the plasma, skin, liver, spleen, kidneys, feces, and urine. In the rabbit, CRCs derived from dietary spinach were found to be distributed in different organs, and Chlide and Pho were the principal Chl metabolites (Hsu et al., 2014). The main CRCs in the liver were found to be Chl, Chlide, Phe, and Pho at $8 \mathrm{~h}$ postfeeding. The gallbladder contained mainly Chlide and Pho at $2 \mathrm{~h}$ post-feeding. Pho was consistently observed in the blood and peaked at $12 \mathrm{~h}$ post-feeding in the rabbit. However, CRC distributions in humans are not completely understood. Dandler et al. (2010) characterized the distribution of Chl- and bacterio-Chl-derived photosensitizers in human plasma and found low levels of cell-bound CRCs; additionally, LDLs, high-density lipoproteins (HDLs), and high-density proteins (HDPs) exhibit different levels of binding to CRCs. Another study showed nearly $100 \%$ binding of HPPH to plasma proteins in cancer patients (Bellnier et al., 2006). Gandul-Rojas et al. (2009) stated that $\mathrm{Chl}$ pigments are transferred from ingested food to micelles, with Pho $a$ being the most micellarized derivative in caco-2 cells. All leafy green vegetables contain thylakoids. Erlanson-Albertsson and Albertsson (2015) reported that spinach is satiating and has been described for the Chl bearing parts, the thylakoids, both in animals and in human. Five grams of extracted thylakoids is equivalent to $100 \mathrm{~g}$ of spinach, and $100 \mathrm{~g}$ of thylakoids contain $185 \mathrm{kcal}$, $26.1 \mathrm{~g}$ protein, $7.24 \mathrm{~g}$ fat, $48.7 \mathrm{~g}$ carbohydrate, $27.9 \mathrm{mg}$ lutein, $730 \mu \mathrm{g}$ zeaxanthin, $3.45 \mathrm{mg}$ beta carotene, $21 \mu \mathrm{g}$ vitamin $\mathrm{A}, 1330 \mu \mathrm{g}$ vitamin $\mathrm{K} 1,6.07 \mathrm{mg}$ vitamin $\mathrm{E}$, and 166 $\mu \mathrm{g}$ folic acid (Eva-Lena et al., 2015). Human bioavailability data on Chls is very limited. The purpose of this research was to study whether short-term treatment with spinach through its satiating affected the appearance of any Chl derivative and distribution of CRCs derived from dietary spinach in human blood. Our assumption was that metabolism and absorption in peripheral blood could be achieved by ingestion of Chl during its passage through the gastrointestinal tract.

\section{Materials and Methods}

\section{Study subjects}

Study subjects included eight non-smoking adults who had no history of any symptoms or chronic diseases, regular use of medication, or drug or alcohol abuse. Subjects ranged in age from 21 to 61 years, and were recruited for the study through advertisements placed at Academia Sinica, Taipei, Taiwan. None of the participants was vegetarian, and all were apparently healthy as indicated by a medical and lifestyle questionnaire. Written instructions were given on the front page of the questionnaire, and each subject was individually instructed on how to fill out the questionnaire to avoid misinterpretation. They all agreed to refrain from taking any dietary supplements during the study, and from taking any medication or consuming any green vegetables that might interfere with the study measurements. All subjects were instructed to maintain the same level of habitual physical activity throughout the study. Subjects completed a 3-day dietary record before the intervention in order to provide information about their dietary intake during the intervention. After they had delivered their dietary record, participants were asked to refrain from eating and drinking for $8 \mathrm{~h}$ prior to blood collection. The protocol and aims of the study were fully explained orally and in writing to participants, who subsequently provided written informed consent. The study was performed according to a protocol approved by the Ethics Committee of the Institute of Biomedical Sciences, Academia Sinica, and written informed consent was obtained from all subjects.

\section{Diet preparation and blood sampling}

The Savoy type of spinach (Spinacia oleracea) has darkgreen, crinkly, curly leaves, and was purchased from three local suppliers in Taipei, Taiwan, for the human study. Fresh bunches were washed with deionized water, the lower part of the stalk was removed, and the leaves were stored in a refrigerator. The fresh leaves ( $1.2 \mathrm{~kg}$ wet weight) were put in a pot and cooked with $2 \mathrm{~L}$ of boiling water for 3 4 min. Participants arrived at the laboratory the next morning at 8 o'clock for anthropometric measurements and blood sampling after an 8-h overnight fast. At this time, they were asked to consume the cooked spinach in one hour. Three hours after eating the spinach, blood samples were again taken from each participant. In order to measure the maximum level of blood CRCs, a single time point blood levels was collected following the meal. Blood was collected in ethylenediaminetetraacetic disodium salt (EDTA-2Na) tubes and plasma obtained by centrifugation at $15,000 \mathrm{~g}$ for $10 \mathrm{~min}$, prior to storage at $-20{ }^{\circ} \mathrm{C}$ until analysis. Blood samples were taken in duplicate, and values from each sample set were averaged. 
Preparation of CRC standards, Phe, Pho, Chlide, and Chlase, and an activity analysis

The CRC analysis of fresh spinach leaves was primarily performed according to our previous procedures (Hsu et al., 2005). Briefly, Chl $a$ and $b$ were purified by chromatography using a CM-Sepharose CL-6B (Firsttec Scientific, New Taipei City, Taiwan). Phe was obtained by adding several drops of acetic acid to $\mathrm{Chl} a$ and $b$. Chlide $a$ and $b$, and Pho $a$ and $b$ were prepared by adding Chlasecontaining extraction fluid to Chl $a$ and $b$, and Phe $a$ and $b$, respectively. Purified Chlide and Pho were obtained after 30 min of reaction. Purified Chl $a$ and $b$ were purchased from Sigma Chemical (St. Louis, MO, USA) and used as a standard control for high-performance liquid chromatography (HPLC). Chl $a$ and $b$ were dissolved in ether, after which a few drops of acetic acid were added for pheophytinization. The solution was dried in a stream of nitrogen gas for $2 \mathrm{~min}$ and then stored at $-80{ }^{\circ} \mathrm{C}$ for later use. The total chlorophyll $(\mathrm{Chl} a+\mathrm{Chl} b)$ in freeze-dried spinach was calculated from the prepared calibration curves of the respective standards.

Nine milliliters of reaction reagent was added to the aforementioned enzyme-containing powder, and the sample was mixed well. The supernatant was collected, and $10 \mathrm{mg}$ of Chl $a$ was added. After sonication, the sample was filtered, and acetone was used to rinse the residue left on the filter paper. The filtrate was collected, and $\mathrm{NaCl}$ was added to saturate the filtrate. Ether was added for extraction, and the extract was dried with nitrogen gas and re-dissolved in acetone for CM-Sepharose column chromatography. Unreacted substances were eluted using acetone at the beginning, followed by washing with $5 \%$ methanol in acetone for Pho, and with $25 \%$ methanol in acetone for Chlide.

Fresh milky spot Ficus leaves were quickly frozen in liquid nitrogen and ground up; $350 \mathrm{ml}$ of $-20^{\circ} \mathrm{C}$ acetone was added for the extraction. Extracts were filtered, dried with nitrogen gas, and stored at $-20^{\circ} \mathrm{C}$. A sample of $160 \mathrm{mg}$ of dry powder was collected, and $5 \mathrm{~mL}$ of extraction reagent was added. A polytron homogenizer was used to homogenize the sample, which was cultured at $37^{\circ} \mathrm{C}$ for 2 $\mathrm{h}$, followed by centrifugation at $15,000 \mathrm{~g}$ for $10 \mathrm{~min}$. The enzyme-containing supernatant was collected. A sample of $0.5 \mathrm{~mL}$ of the supernatant was collected, and $2 \mathrm{~mL}$ of the reaction reagent and $0.2 \mathrm{~mL}$ of ether were added and mixed well at $37^{\circ} \mathrm{C}$. A mixture of acetone $/ n$-hexane $/ 10 \mathrm{mM}$ aqueous $\mathrm{KOH}(4: 6: 1 ; \mathrm{v} / \mathrm{v})$ was added and shaken well. The sample was separated into two layers: an upper layer containing hydrophilic Chlide in the acetone phase and a lower layer containing hydrophobic Pho in the hexane phase. The two layers were analyzed using a spectrophotometer.

\section{Extraction of CRCs in blood samples and HPLC}

Freeze-dried blood samples were prepared, and $80 \%$ acetone was added in a ratio of $1: 20(\mathrm{w} / \mathrm{v})$ for grinding. Filter paper (150 mm, TOYO Advante, Japan) was used to filter out impurities, and then a crude extract of CRCs was obtained. The crude extract was placed in a separating funnel, and ethyl ether $(1: 20 \mathrm{v} / \mathrm{v})$ and $10 \% \operatorname{KCl}(1: 10, \mathrm{v} / \mathrm{v})$ were added. The sample was mixed and then left to stand for a few minutes until it had separated. The upper-layer fluid was collected. Distilled-deionized water (d.d. $\mathrm{H}_{2} \mathrm{O}$, $1: 20, \mathrm{v} / \mathrm{v})$ and $10 \% \mathrm{KCl}(1: 10, \mathrm{v} / \mathrm{v})$ were added and mixed, and then sample was allowed to sit for several minutes. After separation, the lower layer was removed, and the upper layer was collected. This experimental procedure was repeated twice. The upper-layer extracts were mixed, and the ethyl ether was removed by rotary evaporation (Buchi Rotavapor R-124, Firsttec Scientific B401L, New Taipei City, Taiwan). The dried sample was then dissolved in ether to make $1 \mathrm{~mL}$ of a pure pigment solution. The solution was filtered with an Anylon filter membrane $(0.22 \mu \mathrm{m}$ aperture; Nylon acrodisk, Gelman, Sigma-Aldrich), and a sample of $25 \mu \mathrm{L}$ of the filtrate was collected for HPLC at $\mathrm{A}_{660 \mathrm{~nm}}$.

Analytical separation was performed on a $5-\mu \mathrm{m}$ Spherisorb ODS-2 $250 \times 40-\mathrm{mm}$ column (C18) using a Waters Model 510 high-pressure pump (Millipore-Waters, Milford, MA, USA). The flow rate was controlled with a Waters Model 680 automated gradient controller. A Waters U6K injector and Waters Dual $\lambda$ Absorbance Detector (model 2487) were used. Solvent A was acetonitrile/methanol $(3 / 1, v / v)$, and solvent $B$ was d.d. $\mathrm{H}_{2} \mathrm{O}$. Pigments were identified at $660 \mathrm{~nm}$ using the retention time and visible absorption characteristics. SISC 2.01 HPLC analysis system software developed by Yehua Technical Institution (Taipei, Taiwan) was used. The absorbance of the pigment solution was measured using a Hitachi U-2000 UV-visible spectrophotometer (Hitachi, Tokyo, Japan) at $350 \sim 750 \mathrm{~nm}$.

\section{Spectroscopic characteristics of CRCs}

$\mathrm{Chl} a$ and $b$ were purified from fresh spinach. The other six derivatives, including Chlide $a$ and $b$, Phe $a$ and $b$, and Pho $a$ and $b$ were obtained using the above methods. Each CRC had a major absorption peak in the blue and red light regions. Chl $a$ and its derivatives had significantly different absorption peaks than those of $\mathrm{Chl} b$ and its derivatives. Absorption peaks of $\mathrm{Chl} a$ and its derivatives ranged 660 665 nm, while those of $\mathrm{Chl} b$ and its derivatives ranged $640 \sim 645 \mathrm{~nm}$ (Hsu et al., 2014). Thus, $660 \mathrm{~nm}$ was used to record changes in CRCs during the component analysis.

\section{Statistical analysis}

Contents of CRCs in the blood are expressed as the mean \pm standard deviation (SD) of triplicate determinations, and statistical analyses were performed using a paired t-test at a 0.05 significant level to compare differences between before and after spinach consumption using SAS statistical software (vers. 9.2; SAS Institute, Cary, NC, USA).

\section{Results}

\section{CRCs in spinach}

The fresh spinach leaf extract yielded nine peaks, including violaxanthin, taraxanthin $(\mathrm{T})$, antheraxanthin (A), lutein (L), zeaxanthi (Z), Chl $b, \mathrm{Chl} a, \alpha$-carotene, and $\beta$-carotene (Fig. 1). Among them, the principle CRCs were $\mathrm{T}, \mathrm{L}, \mathrm{Chl} b$, and Chl $a$. Chls were quantified as described previously (Simonich et al., 2008). By eating $1.2 \mathrm{~kg}$ of the 
312

spinach-supplemented diet, the Chl intake of each subject was calculated to be $1286 \mathrm{mg} \mathrm{Chl}$ in the study. This amount corresponds to approximately $1.55 \mathrm{mg}$ total Chls per $\mathrm{kg}$ of body weight, which would be equivalent to $110 \mathrm{mg} \mathrm{Chl} \mathrm{for}$ a 70-kg human (Fernandes et al., 2007). The present study shows that absorption of CRCs equivalents apparently occurred, and that variations among the eight subjects were minimal. It was reported that the ratio of $\mathrm{Chl} a$ to $b$ is a minimum of three to one in green leafy tissues (Ferruzzi $e t$ al., 2007). In our study, the tested sample contained a Chl a content that was 4 times higher than the $\mathrm{Chl} b$ content, while $\mathrm{Chl} a$ is a universal pigment and its counterpart $\mathrm{Chl} b$ is found in the higher plants. Chls and other pigments are photosynthetic compounds synthesized and stored in plastidic membranes of plants, and Chl degradation pathways in plants are as different as dietary $\mathrm{Chl}$ metabolism pathways in humans. Pho a is concentrated in mitochondria. Both $\mathrm{Chl} a$ and $\mathrm{Chl} b$ contain a phytol tail and an $\mathrm{Mg}$ ion, which impede entry into cells or even binding to the outer membrane of mitochondria.

\section{CRCs in blood}

Eight peaks were detected in blood at $3 \mathrm{~h}$ after consuming the spinach, where Phe derivatives (nos. 4 6) and Pho derivatives (nos. 7 and 8) had longer retention times (26 57 $\mathrm{min}$ ) in the column, and the other three peaks were lutein (peak 1), zeaxathin (peak 2), and an unknown (peak 3) (Table 1). CRCs with high polarity, including Phe $a$ and $b$ and $\mathrm{Chl} a$ and $b$, were eluted at an earlier time (26 33 min). CRCs with low polarity, including Pho $a$ and $b$ and Chlide $a$ and $b$ were eluted at $38 \sim 57 \mathrm{~min}$. Significant changes in blood CRCs were observed before and after the intervention period. Table 2 shows that all $\mathrm{Chl}$ derivates in subject no. 3 were significantly higher after consuming the spinach compared to before being fed the spinach. Blood CRCs and pigments in subject no. 3 were mainly lutein, zeaxathin, and an unknown (peaks 1 3) and two Phe derivates (peaks 4 and 5), but did not contain one Phe derivative (peak 6) or any Pho derivates (peaks 7 and 8)

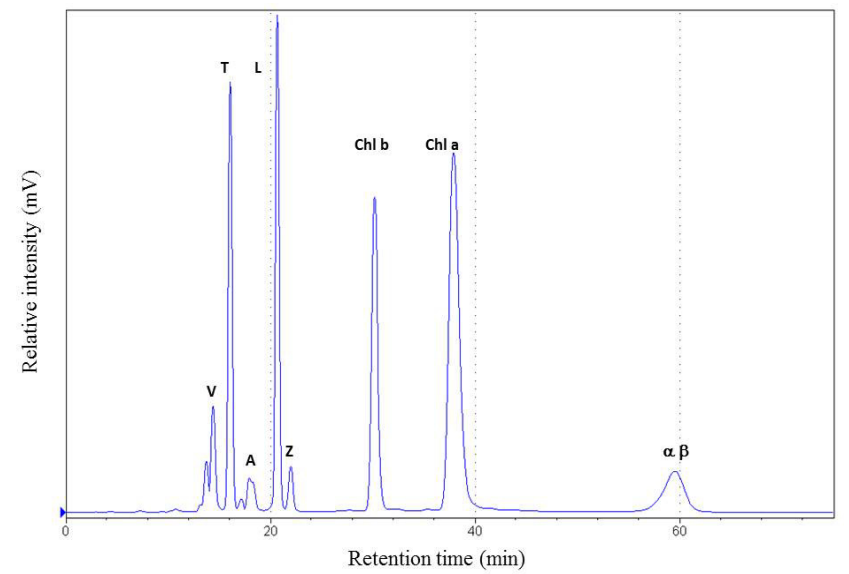

Fig. 1. Representative HPLC chromatograms of chlorophyll (Chl) components in fresh spinach. $\mathrm{V}$, violaxanthin; $\mathrm{T}$, taraxanthin; A, antheraxanthin; L, lutein; Z, zeaxanthin; Chl $b$, chlorophyll $b$; Chl $a$, chlorophyll $a$; a, $\alpha$-carotene; b, $\beta$ carotene before being fed the spinach (Fig. 2). However, there were significant increases in concentrations of all CRCs, especially peaks $6(13,474 \pm 984), 7(52,988 \pm 1894)$, and 8 $(68,683 \pm 1326)$ after ingestion of spinach (Table 2), indicating that Chls were taken up by the subjects, and Pho might be more easily absorbed. Since Pho and Phe derivates are not endogenously produced in humans, their presence in the human body is of exogenous origin, and they are almost exclusively ingested in the diet as preformed Chls. The exogenous origin of Chls in humans makes it reasonable to assume that increased concentrations of Pho and Phe derivates found after the intervention were due to increased intake in this period. In addition, Chl $a$ and $b$ may be converted to Chlide, Pho, and Phe by enzymes or the microflora in the intestines. These data also suggest that CRCs might have transformed into Phe and Pho, and been absorbed as those two forms in the intestines. Aprahamian et al. (1993) reported that rats injected with Pho $a$ showed a dramatic peak of Pho $a$ in the ileum at the 6 8-h time point, suggesting that Pho might be concurrently found within the enterohepatic circulation. Previously, we also showed that only Pho $a$ and $b$ were consistently found in rabbit blood (Hsu et al., 2014), and Chls could enhance the ability of human lymphocytes to resist $\mathrm{H}_{2} \mathrm{O}_{2}$-induced oxidative damage, especially by Pho $a$ and $b$ (Hsu et al., 2005). Pho acts by way of an ion-chelation effect to reduce metal-induced hydroxyl radical generation, thus protecting DNA from oxidative damage (Lanfer-Marquez et al., 2005). Both Pho $a$ and $b$ may exert their antioxidative capacities by the porphyrinization of reactive oxygen species (ROS), and also by their inherent ion-chelating capacity. The hydrophobic characteristics of CRCs differ, which could influence their uptake and cellular distributions (Ferruzzi et al., 2007; Sakdarat et al., 2009). In general, it appears that passive diffusion of Pho $a$ into cells is counteracted by the active transport of Pho $a$ out of cells by ATP-binding cassette $(A B C)$ transporters, such as the breast cancer resistance protein (ABCG2) (Jonker et al., 2002).

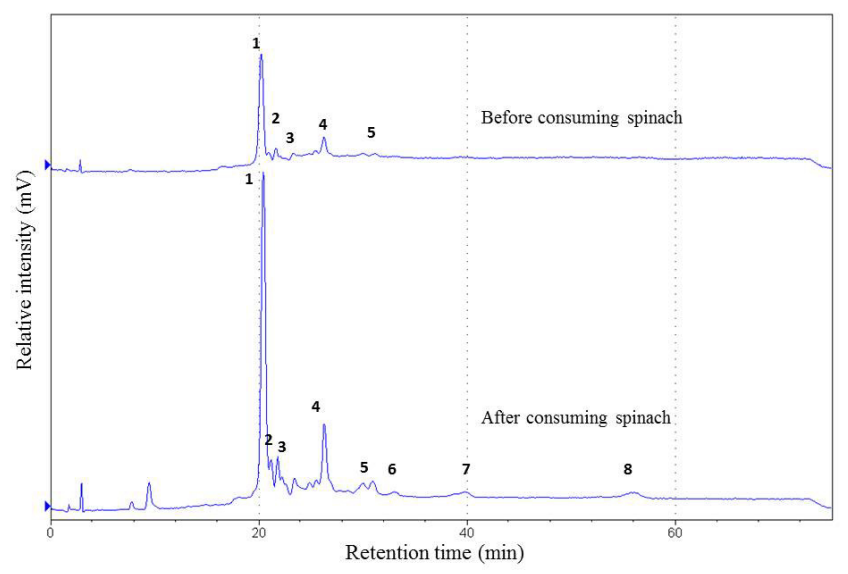

Fig. 2. Changes in blood chlorophyll (Chl)-related compounds (CRCs) and pigments from dietary spinach in subject number 3. Note that the Chl peaks identified and numbered $1 \sim 8$ are also shown in Table 2 
Table 1. Retention time and absorbance of pigments at $3 \mathrm{~h}$ after consuming spinach

\begin{tabular}{cccc}
\hline Peak & $\begin{array}{c}\text { Retention time } \\
(\mathrm{min})\end{array}$ & $\begin{array}{c}\text { Absorbance } \\
(\mathrm{nm})\end{array}$ & Lutein \\
\hline 1 & 20.247 & $667,469,441,419$ & Zeaxanthin \\
2 & 21.617 & $667,392,371$ & Pheophytin (Phe) \\
3 & 23.348 & 668,400 & derivatives \\
4 & 26.320 & 667,409 & Pheophorbide (Pho) \\
5 & 31.187 & 667,408 & derivatives \\
\hline
\end{tabular}

Table 2. Changes in blood chlorophyll-related compounds (CRCs) and pigments from dietary spinach in subject number 3

\begin{tabular}{|c|c|c|c|c|c|c|c|c|}
\hline \multirow{2}{*}{$\begin{array}{l}\text { Dietary } \\
\text { spinach }\end{array}$} & \multirow{2}{*}{$\begin{array}{l}\text { Peak 1 } \\
\text { (lutein) }\end{array}$} & \multirow{2}{*}{$\begin{array}{c}\text { Peak } 2 \\
\text { (zeaxanthin) }\end{array}$} & \multirow{2}{*}{$\begin{array}{c}\text { Peak 3 } \\
\text { (unknown) }\end{array}$} & \multicolumn{2}{|c|}{ Phe derivatives } & \multicolumn{3}{|c|}{ Pho derivatives } \\
\hline & & & & Peak 4 & Peak 5 & Peak 6 & Peak 7 & Peak 8 \\
\hline Before & $95420 \pm 296$ & $7749 \pm 56$ & $4211 \pm 44$ & $19900 \pm 317$ & $6876 \pm 85$ & 0 & 0 & 0 \\
\hline After & $656004 \pm 12836$ & $51971 \pm 2007$ & $36257 \pm 1378^{*}$ & $188934 \pm 5239^{*}$ & $78321 \pm 3752$ & $13474 \pm 984^{*}$ & $13474 \pm 984^{*}$ & $68683 \pm 1326$ \\
\hline
\end{tabular}

Peak area calculated by SISC 2.01 chromatography data system software (Yehua Technical Institute, Taipei, Taiwan) is expressed as mean \pm standard deviation. Data were analyzed by $t$-test, and asterisk indicates statistical significance at $p<0.05$.

Table 3. Blood chlorophyll-related compounds (CRCs) and pigments at $3 \mathrm{~h}$ after consuming spinach in all participants

\begin{tabular}{|c|c|c|c|c|c|c|c|c|}
\hline \multirow{2}{*}{ Subject } & \multirow{2}{*}{ Peak 1 (lutein) } & \multirow{2}{*}{$\begin{array}{c}\text { Peak } 2 \\
\text { (zeaxanthin) }\end{array}$} & \multirow{2}{*}{$\begin{array}{c}\text { Peak } 3 \\
\text { (unknown) }\end{array}$} & \multicolumn{3}{|c|}{ Phe derivatives } & \multicolumn{2}{|c|}{ Pho derivatives } \\
\hline & & & & Peak 4 & Peak 5 & Peak 6 & Peak 7 & Peak 8 \\
\hline 1 & 56 & 48 & 34 & 20 & 18 & 7 & 0 & 0 \\
\hline 2 & 34 & 16 & 13 & 25 & 17 & 17 & 0 & 0 \\
\hline 3 & 59 & 44 & 56 & 69 & 29 & 92 & 40 & 23 \\
\hline 4 & 65 & 74 & 35 & 62 & 23 & 46 & 16 & 23 \\
\hline 5 & 95 & 100 & 43 & 100 & 76 & 68 & 66 & 100 \\
\hline 6 & 92 & 72 & 100 & 61 & 39 & 100 & 100 & 46 \\
\hline 7 & 54 & 35 & 26 & 60 & 63 & 34 & 20 & 23 \\
\hline 8 & 100 & 74 & 53 & 42 & 100 & 67 & 20 & 18 \\
\hline
\end{tabular}

Relative peak high (\%) is calculated as relative value to its highest level of 100 in each peak.

Mean plasma CRC levels of eight peaks calculated as the relative peak height (\%) from all subjects are shown in Table 3. Major CRC distributions in subject number 5 were observed in peaks 2,4 , and 8 , which reached their highest levels of 100 . Relative values of peaks 3, 6, and 7 also reached 100 in subject number 6. Peaks 1 and 5 with the highest level of 100 were also found in subject number 8 . Values of all peaks were relatively steadily distributed in blood samples of subjects 3, 4, and 7. Chls are lipophilic, which may result in singular interactions of each compound with the hydrophobic interior of enterocyte membranes and would affect the uptake and distribution to peripheral tissues. The amount and type of compounds found in the peripheral blood can be significantly lower than the amount absorbed by the portal vein. Surprisingly, Pho derivatives were not found in subjects 1 or 2 who had extremely low levels, suggesting that the amounts of CRCs in the enterohepatic circulation had a very low concentration, even though they rapidly appeared in the blood. Instead, $\mathrm{Chl} a$ might have been converted to Pho prior to absorption, and Phe was degraded to Pho by removal of the phytyl group in the intestines by microbacteria. Further studies are necessary to confirm this. Chl $a$ and $b$ are respectively converted to Phe a and $\mathrm{b}$ during the digestive process (Ferruzzi et al., 2006).
Although $\mathrm{Chl} b$ is thought to be more stable against being digested than Chl a (Gallardo-Guerrero et al., 2008), Chl a and $b$ are less stable against the digestive process than $\mathrm{Mg}$ free Chl derivatives (Gandul-Rojas et al., 2009). In our study, Phe, Pho, and other metabolites were found in the blood throughout the study period and peaked at $3 \mathrm{~h}$ postfeeding, suggesting that the conversion of $\mathrm{Chl}$ to $\mathrm{CRCs}$ is a rapid process. Compared to other nutrients in humans, the polarity of Chls is low. Therefore, Chls in mammals may be converted into Phe and Pho derivatives. Chls may be directly transformed to Phe derivatives in the human stomach because of the acidic environment. Phe derivatives are further converted into Pho derivatives in the intestines, then absorbed similarly to the lipid metabolic pathway and released into the bloodstream.

Spinach has high nutritional value, especially when fresh or quickly boiled. It is a rich source of vitamins and minerals, and provides both anti-inflammatory and antioxidant benefits (Edenharder et al., 2001; Song et al., 2010). Many biological functions, including antioxidation, antitumor, and anti-aging, have recently been attributed to CRCs. De Vogel et al. (2005) demonstrated for the first time that spinach and Chl inhibit the cytotoxicity and proliferation of 
314

colonic cells in rats. Simonich et al. (2008) suggested that the antitumor activities of certain $\mathrm{Chl}$ derivatives are mediated via inhibition of absorption of specific carcinogens. Diets rich in Chls may prevent the development of hepatocellular carcinoma (Hsu et al., 2008). McQuistan et al. (2012) determined that a diet containing $10 \%$ spinach substantially suppressed tumor development in multiple target organs (small intestines, colon, skin, spleen, liver, and lungs) in rats, when this diet was fed for 34 weeks following carcinogen treatment. The mechanisms and intensities of the protective effects may depend on the particular Chl derivative used. Do CRCs have specific biological functions in vivo? The therapeutic potential of CRCs as anti-inflammatory agents for use in certain disorders and a full framework of CRC metabolic pathways in the human body are worthy of further investigation. To our knowledge, this is the first study to provide evidence of the distribution of CRCs derived from dietary spinach in human blood. Thus, some of the beneficial effects of CRCs might be mediated through their effects on metabolic pathways. Binding of CRCs to other nutrients or trace metal ions in the body to mediate their biological functions may be a potential future target for possible clinical applications.

Effects of sex and age on blood CRCs at $3 \mathrm{~h}$ after consuming spinach

In the current study, we investigated the extent to which spinach affected concentrations of CRCs and pigments in the blood of healthy men and women. To explore the possibility that sex and age influence $\mathrm{Chl}$ derivatives in the blood, the effects of sex and age on blood CRCs and pigments were studied. We found that there tended to be slight differences in digested Chls throughout the 3-h period of blood collection in terms of sex and age, which shows that there were no significant differences in most of the peaks between the male and female groups (Table 4) or the $<35$ - and $>35$-year-old groups (Table 5). It is noteworthy that relatively high CRC levels were observed in females; in particular, significantly higher Pho derivatives (peaks 7 and 8) were detected in females $(83 \pm 16 \%$ and $73 \pm 19 \%)$ than males $(16 \pm 7 \%$ and $15 \pm 4 \%)$. The blood contained a significantly higher level of Phe (peak 5 ) in the 36 61-year-old group (64 16\%) than that of the 21 35year-old group $(35 \pm 8 \%)$. This could have been due to different compliance and/or random differences in Chl metabolism between the groups. The variation possibly illustrates that high dietary intake of vegetables determines CRC concentrations. Women have higher levels of Chl antioxidant may be due to consuming more vegetables in general and leading to higher levels of Chls. It is unlikely that the age and sex differences in this study affected the distributions of CRCs derived from dietary spinach in the human blood. Because the test diet only substituted a part of the habitual diet, the CRC contents in the test diet cannot be regarded as being the sole source of dietary CRCs. The control of additional dietary spinach intake could potentially also have influenced plasma CRC concentrations in these groups.

No adverse events or effects of spinach intake or CRCs concentrations were reported in any subject. In fact, there are no data in the literature indicating that changes in CRCs that were induced in the present study would have any negative impacts on human health. Chls are normal constituents of the human diet, especially from green vegetables. Moreover, Chls and their derivatives have also been used as additives for food-coloration purposes. Chls are available as over-the-counter drugs, and such drug types are widely used to control body, fecal, and urinary odors among geriatric patients (McQuistan et al., 2012). Pho compounds were found to be more effective than Phe or Chlide, and might act as free-radical scavengers and chelating agents to protect humans from oxidative damage (De Vogel et al., 2005). Although a small number of participants were investigated in this study, we have shown that the intake of usual dietary portions of green vegetables,

Table 4. Effects of sex on blood chlorophyll-related compounds (CRCs) and pigments at $3 \mathrm{~h}$ after consuming spinach

\begin{tabular}{|c|c|c|c|c|c|c|c|c|}
\hline \multirow{2}{*}{ Sex } & \multirow{2}{*}{$\begin{array}{l}\text { Peak } 1 \\
\text { (lutein) }\end{array}$} & \multirow{2}{*}{$\begin{array}{c}\text { Peak } 2 \\
\text { (zeaxanthin) }\end{array}$} & \multirow{2}{*}{$\begin{array}{c}\text { Peak 3 } \\
\text { (unknown) }\end{array}$} & \multicolumn{2}{|c|}{ Phe derivatives } & \multicolumn{3}{|c|}{ Pho derivatives } \\
\hline & & & & Peak 4 & Peak 5 & Peak 6 & Peak 7 & Peak 8 \\
\hline $\begin{array}{l}\text { Male } \\
(\mathrm{n}=3)\end{array}$ & $61 \pm 15^{a}$ & $48 \pm 16^{a}$ & $36 \pm 9^{b}$ & $46 \pm 12^{a}$ & $42 \pm 13^{a}$ & $44 \pm 20^{\mathrm{a}}$ & $16 \pm 7^{b}$ & $15 \pm 4^{b}$ \\
\hline $\begin{array}{c}\text { Female } \\
(\mathrm{n}=9)\end{array}$ & $94 \pm 20^{a}$ & $86 \pm 13^{a}$ & $72 \pm 24^{a}$ & $80 \pm 23^{a}$ & $58 \pm 14^{a}$ & $84 \pm 21^{a}$ & $83 \pm 16^{a}$ & $73 \pm 19^{a}$ \\
\hline
\end{tabular}

Relative peak high (\%) is calculated as relative value to its highest level of 100 in each peak. Changes of CRCs from dietary spinach were tested by $\mathrm{t}$-test, and different superscripts indicate statistical significance at $p<0.05$.

Table 5. Effects of age on blood chlorophyll-related compounds (CRCs) and pigments at $3 \mathrm{~h}$ after consuming spinach

\begin{tabular}{|c|c|c|c|c|c|c|c|c|}
\hline \multirow{2}{*}{ Age } & \multirow{2}{*}{$\begin{array}{l}\text { Peak } 1 \\
\text { (letein) }\end{array}$} & \multirow{2}{*}{$\begin{array}{c}\text { Peak 2 } \\
\text { (zeaxanthin) }\end{array}$} & \multirow{2}{*}{$\begin{array}{c}\text { Peak 3 } \\
\text { (unknown) }\end{array}$} & \multicolumn{2}{|c|}{ Phe derivatives } & \multicolumn{3}{|c|}{ Pho derivatives } \\
\hline & & & & Peak 4 & Peak 5 & Peak 6 & Peak7 & Peak 8 \\
\hline $\begin{array}{c}\text { 21-35 year- } \\
\text { old } \\
(n=4)\end{array}$ & $68 \pm 19^{a}$ & $62 \pm 23^{a}$ & $45 \pm 18^{a}$ & $53 \pm 16^{a}$ & $35 \pm 8^{b}$ & $48 \pm 15^{\mathrm{a}}$ & $36 \pm 9^{a}$ & $34 \pm 10^{\mathrm{a}}$ \\
\hline $\begin{array}{c}\text { 36-61 year- } \\
\text { old } \\
(n=4)\end{array}$ & $71 \pm 21^{a}$ & $51 \pm 18^{a}$ & $45 \pm 11^{a}$ & $57 \pm 12^{a}$ & $64 \pm 16^{a}$ & $64 \pm 20^{a}$ & $27 \pm 8^{a}$ & $21 \pm 4^{a}$ \\
\hline
\end{tabular}

Relative peak high (\%) is calculated as relative value to its highest level of 100 in each peak. Changes of CRCs from dietary spinach were tested by t-test, and different superscripts indicate statistical significance at $p<0.05$. 
such as spinach, is likely to provide systemic exposure to Chls and their derivatives in the blood. However, questions regarding the recovery and biodistribution of the digested Chl derivatives in other organs or tissues of human deserve further investigation.

\section{Conclusions}

This study confirms that Chls obtained by ingestion can be absorbed by the human body, and Phe and Pho are two major CRCs in human blood. These compounds occur in relatively major amounts in green vegetables and have been shown to have large bioavailability, which is likely to have impacts on human health. Our data also expand our understanding of the metabolism and biodistribution of CRCs in the human body, and some of the beneficial effects of Chl derivates might be mediated through their effects on metabolic pathways.

\section{References}

Aprahamian M, Evrard S, Keller P, Tsuji M, Balboni G, Damgé C, Marescaux J (1993). Distribution of pheophorbide A in normal tissues and in an experimental pancreatic cancer in rats. Anticancer Drug Design 8:101-114.

Bellnier DA, Henderson BW, Pandey RK, Potter WR, Dougherty TJ (1993). Murine pharmacokinetics and antitumor efficacy of the photodynamic sensitizer 2-[1-hexyloxyethyl]-2-devinyl pyropheophorbide-a (HPPH). Journal of Photochemistry and Photobiology B 20:55-61.

Bellnier DA, Greco WR, Loewen GM, Nava H, OseroffAR, Dougherty TJ (2006). Clinical pharmacokinetics of the PDT photosensitizers porfimer sodium (Photofrin), 2-[1-hexyloxyethyl]-2-devinyl pyropheophorbide-a (photochlor) and 5-ALA-induced protoporphyrin IX. Lasers in Surgery and Medicine 38:439-444.

Chernomorsky S, Segelman A, Poretz RD (1999). Effect of dietary chlorophyll derivatives on mutagenesis and tumor cell growth teratogen. Carcinogens and Mutagens 19:313-322.

Dandler J, Wilhelm B, Scheer H (2010). Distribution of chlorophyll- and bacteriochlorophyll-derived photosensitizers in human blood plasma. Photochemistry and Photobiology 86:182-193.

De Vogel J, Jonker-Termont DS, Van Lieshout EM, Katan MB, Van der Meer R (2005). Green vegetables, red meat and colon cancer: Chlorophyll prevents the cytotoxic and hyperproliferative effects of haem in rat colon. Carcinogens 26:387-393.

Edenharder R, Keller G, Platt KL, Unger KK (2001). Isolation and characterization of structurally novel antimutagenic flavonoids from spinach (Spinacia oleracea). Journal of Agriculture and Food Chemistry 49:2767-2773.

Erlanson-Albertsson C, Per-ÅkeA (2015). The use of green leaf membranes to promote appetite control, suppress hedonic hunger and loose body weight. Plant Foods and Human Nutrition 70:281-290.

Eva-Lena S, Egecioglu E, Landin-Olsson M, Erlanson-Albertsson C (2015). Consumption of thylakoid-rich spinach extract reduces hunger, increases satiety and reduces cravings for palatable food in overweight women. Appetite 91:209-219.
Fernandes TM, Gomes BB, Lanfer-Marquez UM (2007). Apparent absorption of chlorophyll from spinach in an assay with dogs. Innovative Food Science \& Emerging Technologies 8:426-432.

Ferruzzi MG, Blakeslee JD (2007). Absorption, and cancer preventative activity of dietary chlorophyll derivatives. Nutrition Research 27:1-12.

Ferruzzi MG, Failla ML, SchwartzSJ (2001).Assessment of degradation and intestinal cell uptake of carotenoids and chlorophyll derivatives from spinach puree using an in vitro digestion and Caco- 2 human cell model. Journal of Agriculture and Food Chemistry 49:2082-2089.

Ferruzzi MG, Lumpkin JL, Schwartz SJ, Failla M (2006). Digestive stability, micellarization, and uptake of beta-carotene isomers by Caco- 2 human intestinal cells. Journal of Agriculture and Food Chemistry 54:27802785.

Gallardo-Guerrero L, Gandul-Rojas B, Mínguez-Mosquera MI (2008). Digestive stability, micellarization, and uptake by caco-2 human intestinal cell of chlorophyll derivatives from different preparations of pea (Pisum sativum L.). Journal of Agriculture and Food Chemistry 56:8379-8386.

Gandul-Rojas B, Gallardo-Guerrero L, Mínguez-Mosquera MI (2009). Influence of the chlorophyll pigment structure on its transfer from an oily food matrix to intestinal epithelium cells. Journal of Agriculture and Food Chemistry 57:5306-5314.

Hsu CY, Chao PY, Hu SP, Yang CM (2013). The antioxidant and free radical scavenging activities of chlorophylls and pheophytins. Food Nutrition Science 4:1-8.

Hsu CY, Chen YH, Chao PY, Hu SP (2008). Naturally occurring chlorophyll derivatives inhibit aflatoxin B1-DNA adduct formation in hepatoma cells. Mutation Research 657:98-104.

Hsu CY, Yang CM, Chen CM, Chao PY, Hu SP (2005). Effects of chlorophyll-related compounds on hydrogen peroxide induced DNA damage within human lymphocytes. Journal of Agriculture and Food Chemistry 53:2746-2750.

Hsu CY, Yeh TH, Huang MY, Chao PY, Yang CM (2014). Organspecific distribution of chlorophyll-related compounds from dietary spinach in rabbits. Indian Journal of Biochemistry and Biophyics 51:388-395.

Jonker J, Buitelaar M, Wagenaar E, Van Der Valk M, Scheffer G, Scheper R (2002). The breast cancer resistance protein protects against a major chlorophyll-derived dietary phototoxin and protoporphyria. Proceedings of the National Academy of Sciences 99:15649-15654.

Lanfer-Marquez UM, Barros RM, Sinnecker P (2005). Antioxidant activity of chlorophylls and their derivatives. Food Research International 38:885-891.

Lin KH, Hsu CY, Huang YP, Lai JY, Huang MY, Yang CM, Chao PY (2013). Chlorophyll-related compounds inhibit cell adhesion and inflammation in human aortic cells. Journal of Medicine Food 16:1-13.

Mazor O, Brandis A, Plaks V, Neumark E, Rosenbach-Belkin V, Salomon Y, Scherz A (2005). WST11, a novel water-soluble bacteriochlorophyll derivative; cellular uptake, pharmacokinetics, biodistribution and vascular-targeted photodynamic activity using melanoma tumors as a model. Photochemistry and Photobiology 81:342-351.

McQuistan TJ, Michael T, Simonich M, Pratt M, Pereira C, Hendricks J, Dashwood R, Williams D, Bailey S (2012). Cancer chemoprevention by dietary chlorophylls: A 12,000-animal dose-dose matrix biomarker 
316

and tumor study. Food and Chemical Toxicology 50:341-352.

Nakamura Y, Murakami A, Koshimizu K, Ohigashi H (1996). Inhibitory effect of pheophorbide a, a chlorophyll-related compound, on skin tumor promotion in ICR mice. Cancer Letter 108:247-255.

Pandey RK, Shiau FY, Sumlin AB, Dougherty TJ, Smith KM (1992). Structure/activity relationships among photosensitizers related pheophorbides and bacteriopheophorbides. Bioorganic \& Medicinal Chemistry Letters 2:491-496.

Sakdarat S, Shuyprom A, Pientong C, Ekalaksananan T, Thongchai S (2009). Bioactive constituents from the leaves of Clinacanthus nutans Lindau. Bioorganic \& Medicinal Chemistry 17:1857-1860.
Simonich MT, McQuistan T, Jubert C, Pereira C, Hendricks JD, Schimerlik M,Zhu B, Dashwood RH, Williams DE, Bailey GS (2008). Low-dose dietary chlorophyll inhibits multi-organ carcinogenesis in the rainbow trout. Food and Chemical Toxicology 46:1014-1024.

Song W, Derito CM, Liu MK (2010). Cellular antioxidant activity of common vegetables. Journal of Agriculture and Food Chemistry 58:6621-6629.

Subramoniam A, Asha VV, Nair SA, Sasidharan SP, Sureshkumar PK, Rajendran KN, Karunagaran D, Ramalingam K (2012). Chlorophyll revisited: anti-inflammatory activities of chlorophyll a and inhibition of expression of TNF-a gene by the same. Inflammation 35:959-966. 